\title{
A Note on the Optimal Unemployment Allowance in the Harris-Todaro Model with Trade Unions
}

\author{
Muneyuki Saito* \\ Graduate School of Economics, Osaka University
}

\begin{abstract}
In this paper, we take an unemployment allowance into account in the Harris-Todaro model with an endogenous urban wage determined by a negotiation between a trade union and a firm. In the standard Harris-Todaro model, no unemployment allowance can yield a first-best optimum. However, we show in our model that a first-best competitive allocation of resources can be attained by the appropriate allowance.
\end{abstract}

\section{Introduction}

Harris and Todaro (1970) have modeled the phenomenon in the developing countries that labor migrates from an rural to an urban sector in spite of urban unemployment. Their model has been extended to various directions until now. Firstly, Bhagwati and Srinivasan (1974) analyze the optimal policies that can eliminate unemployment. They show that a uniform wage subsidy or a wage subsidy in manufacturing sector combined with an agricultural production subsidy can attain a first-best solution in the standard Harris-Todaro model.

On the other hand, Calvo (1978) incorporates an urban trade union which negotiates a wage rate in the Harris-Todaro model, and shows that there exists no optimal employment subsidy and wage subsidy which can achieve full employment, while an rural-urban migration tax leads an economy to a first-best optimum. Quibria (1988) extends Calvo's model to (i) introduce the informal sector in an urban sector, (ii) consider the risk-averse individual, (iii) assume the alternative earning of the union members as the informal wages. He examines whether an employment subsidy can attain a first-best optimum so that full employment is realized in an economy. Chau and Khan (2001) prove formally that the first-best optimum is attained by the combination of a revenue-neutral employment subsidy and ad valorem wage tax in Quibria's model.

In the standard Harris-Todaro model, however, it is implicitly assumed that the unemployed can live their life by supports from other workers who earn positive income. Yabuuchi (1996), from the awareness of this issue,

Received 21 December 2005; received in revised form 9 June 2006; accepted 13 July 2006

*E-mail : bg063sm@mail2.econ.osaka-u.ac.jp

I would like to thank Kenzo Abe and Hiroshi Ohta for many useful comments. However, I am responsible for any unintented errors. 
introduces an unemployment allowance to transfer income to the unemployed into the Harris-Todaro model. The purpose in his paper is to examine the welfare effects of wage subsidies but dose not investigate a possibility of the optimal allowance ${ }^{1)}$.

In this paper, we reformulate Calvo's model and take account of an unemployment allowance. We revise trade union objective function in such a way that the unemployed of the union members obtain an unemployment allowance ${ }^{2}$. We show that the government can also attain a first-best optimum by the suitable allowance, while an rural-urban migration tax leads an economy to a first-best optimum in Calvo's model ${ }^{3)}$.

We set up a model in the next section. Then, in section 3, we analyze the case where the migration is determined by an expected wage. Section 4 deals with the case where the migration is determined by an expected utility. Conclusion is given by the final section.

\section{The model}

We suppose a small open economy that faces given international prices. Thus, we can choose units of measurement in such a way as to allow that all international prices of goods are one. There are the monopolistic trade union and the firms in an urban sector. In the first stage, the trade union determines the wage, and in the second stage, the firms decide the labor employment. In this economy, there are the urban sector and the rural sector.

The manufacturing good is produced in the urban sector and the agricultural good is produced in the rural sector. The production functions in each sector are expressed respectively by

$$
\begin{aligned}
X_{u}=F\left(L_{u}\right) & =L_{u}^{a}, \quad 0<a<1, \\
X_{r} & =G\left(L_{r}\right),
\end{aligned}
$$

where $L_{u}$ and $L_{r}$ are the labor employment in an urban and a rural sector, respectively, and $X_{u}$ and $X_{r}$ are the outputs in an urban and a rural sector, respectively. Furthermore, $F$ and $G$ are continuously differentiable and the marginal productivity of labor is positive and strictly decreasing.

1) Temple (2005) examines an unemployment allowance in the standard Harris-Todaro model. However, there is no paper that examines an optimal unemployment allowance in a model.

2 ) Alternative incomes of the trade union members are the rural wage in Calvo's model and the informal wage in Quibria's model, respectively. We follow the new microeconomics literatures of trade union behavior, which incorporate unemployment allowance in an objective function of the trade union. See, for example, Oswald (1985).

3 ) The structure of our model is identical to that of Quibria's model, in a sense that unemployment allowance can be regarded as the informal sector's wage in Quibria's model. The informal sector's wage is always equal to the fixed technical coefficient of the informal sector in Quibria's model. So the government has to employ some policy to change the fixed technical coefficient of the informal sector in order to control the informal sector's wage. But we think that it is not so easy to change the fixed technical coefficient of the informal sector. In our model we introduce unemployment allowance, which can be controlled more easily by the government. In addition, Quibria (1988) doesn't analyze the optimal wage rate of the informal sector. 
The maximization problem of the urban firms is $\max _{L u} F\left(L_{u}\right)-w_{u} L_{u}$, where $w_{u}$ is the urban wage rate. The necessary condition to maximize profits is $w_{u}=F^{\prime}\left(L_{u}\right)=a L^{a-1}$. This necessary condition is rewritten as for the labor demand function such as $L_{u}^{d}=\left(F^{\prime}\right)^{-1}\left(w_{u}\right)=f\left(w_{u}\right)$, where $L_{u}^{d}$ is an optimal labor employment in the urban sector. By assumption of the urban production function, the labor demand function is

$$
L_{u}^{d}=\left(\frac{a}{w_{u}}\right)^{1 /(1-a)},
$$

and, the elasticity of the labor demand is

$$
-\frac{\partial L^{d}}{\partial w_{u}} \frac{w_{u}}{L_{u}}=\frac{1}{1-a} .
$$

We assume the following restriction:

$$
0<w_{u}<\infty .
$$

The profit maximization problem in the rural sector implies

$$
G^{\prime}\left(L_{r}\right)=w_{r},
$$

where $w_{r}$ is the rural wage rate. That is, the rural wage is equal to the marginal productivity of labor in the rural sector. It is assumed that the labor demand function is expressed by $L_{r}=(G)^{-1}\left(w_{r}\right)=g\left(w_{r}\right)$, where $g$ is defined on a positive real line and have the properties of $\lim _{w_{r} \rightarrow 0} g\left(w_{r}\right)=\infty$ and $\lim _{w_{r} \rightarrow 0} g\left(w_{r}\right)=0$.

The indirect utility function of each individual, $U$, is defined as the function of earnings. In the same way as described in Quibria (1988), we assume that it has the following properties:

$$
U^{\prime}>0, U^{\prime \prime} \leqq 0, \quad \text { and } U(0)=0 .
$$

If $U^{\prime \prime}=0$, then the individual is risk-neutral. As following Quibria (1988), the objective function of the trade union, $U^{T}$, is presented by

$$
U^{T}\left(L_{u}, w_{u}, b\right)=L_{u}\left[U\left(w_{u}\right)-U(b)\right],
$$

where $b$ is the level of unemployment allowance ${ }^{4)}$. Let define the unemployed labor forces as $L_{u}^{*}$, the total labor forces in the urban sector, $N_{u}$, is defined as $N_{u}=L_{u}+L_{u}^{*}$. The job acquisition rate in the urban sector is defined as the rate of the employed labor forces for the total urban labor forces, therefore,

$$
\lambda \equiv \frac{L_{u}}{N_{u}} .
$$

If there doesn't exist the difference between an expected utility in the urban and in the rural sector, that is, an expected utility in the urban sector is equal to that in the rural sector, then the labor migration will not occur. The migration condition is in equilibrium, thus,

$$
U\left(w_{r}\right)=\lambda U\left(w_{u}\right)+(1-\lambda) U(b) .
$$

Since the labor is distributed to each sector, the labor constraint is

4) We consider that unemployment benefit is funded by the profit tax or the lumpsum tax. But since these policies cannot influence the equilibrium conditions, we do not express explicitly these policies. In addition, the government doesn't in fact have to collect and pay the allowance, since there is no unemployment if the allowance is the optimal level. 
Muneyuki Saito : A Note on the Optimal Unemployment Allowance in the Harris-Todaro Model with Trade Unions

$$
L=L_{r}+N_{u}=L_{r}+\frac{L_{u}}{\lambda},
$$

where $L$ is the labor endowment in this economy and fixed.

The trade union is a utility maximizer subject to the labor demand function of the manufacturing sector that is obtained from the first-order condition in firms' profit maximization problem. The maximum problem of the trade union is

$$
\max _{w_{u}} U^{T}\left(L_{u}, w_{u}, b\right)=L_{u}\left[U\left(w_{u}\right)-U(b)\right] \text {, s.t. } L_{u}=L_{u}^{d}=f\left(w_{u}\right) .
$$

We get the following first-order condition:

$$
\frac{d U^{T}}{d w_{u}}=\frac{\partial U}{\partial w_{u}}+\frac{\partial U}{\partial L_{u}} \frac{d L_{u}^{d}}{d w_{u}}=0 .
$$

Utilizing the explicit functional form of the trade union utility, we can

rewrite the condition: ${ }^{5)}$

$$
\frac{d U^{T}}{d w_{u}}=L_{u}^{d} U^{\prime}\left(w_{u}\right)+\left[U\left(w_{u}\right)-U(b)\right] \frac{d L_{u}^{d}}{d w_{u}}=0 .
$$

In the following sections, we analyze each case that the migration condition is dependent on an expected income or an expected utility.

\section{The case of an expected income}

We examine in this section and the following section whether the optimal unemployment allowance exists in the above basic model. We assume the specific functional form in the following on each of the cases that the migration equilibrium condition is dependent on expected income or expected utility.

If the utility function of an individual is, for simplicity, $U=w$ when he is risk-neutral, then the utility function of a trade union is given by $U^{T}=L_{u}\left(w_{u}-b\right)$. Thus, the first-order condition in the utility maximization of the trade union, (12), is rewritten as

$$
\frac{d U^{T}}{d w_{u}}=L_{u}^{d}+\frac{d L_{u}}{d w_{u}}\left(w_{u}-b\right)=0 .
$$

Finally, taking advantage of (3) and (4), we can rewrite (13) as

$$
w_{u}=\frac{b}{a} .
$$

5 ) The second-order condition is

$$
\frac{d^{2} U^{T}}{d w_{u}^{2}}=L_{u}^{d} U^{\prime \prime}+2 U^{\prime} \frac{d L_{u}^{d}}{d w_{u}}+\left[U\left(w_{u}\right)-U(b)\right] \frac{d^{2} L_{u}^{d}}{d w_{u}^{2}} .
$$

If the urban production function is also specified by $X_{u}=L_{u}^{a}$, then $d^{2} L_{u}^{d} / w_{u}^{2}<0$. Thus, the second-order condition that $d^{2} U^{T} / w_{u}^{2}<0$ is satisfied. 


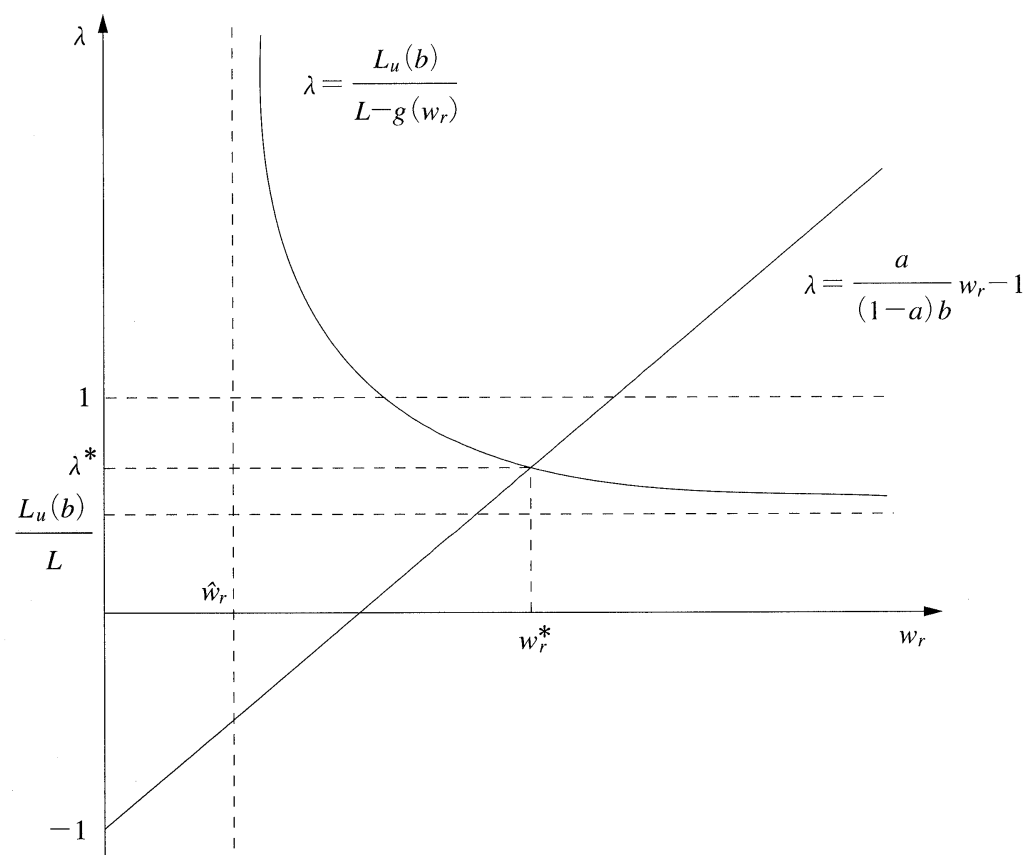

Figure 1 The determination of $\lambda$ and $w_{r}$

(14) is also renewed as $w_{u}-b=b(1-a) / a$. This implies that $w_{u}>b$, as far as unemployment benefits is positive, $b>0$. In addition, from (14), as $b \rightarrow 0, w_{u} \rightarrow 0$ and as $b \rightarrow \infty, w_{u} \rightarrow \infty$. Given that $w_{r}$ exists in a closed interval of $[0 ; \infty]$, there is an optimal unemployment allowance satisfying $w_{r}=w_{u}>b$. In other words, as $w_{c}$ is defined as the competitive wage rate which bring about the competitive equilibrium allocation, there is the optimum of an unemployment allowance leading to $w_{c}=w_{u}=w_{r}>b$. Next, we show that the optimal unemployment allowance exists such as $w_{c}=w_{u}=w_{r}$.

In the case of a risk-neutral individual, substituting $U=w_{u}$ and (14) for migration condition (10) and arranging it, we obtain

$$
\lambda=\frac{a}{(1-a)} \frac{w_{r}-b}{b} .
$$

Replacing (11) by (3) and (14), the labor constraint is reformulated to be

$$
\lambda=\frac{L_{u}(b)}{L-g\left(w_{r}\right)}=\frac{\left(\frac{b}{a^{2}}\right)^{-1 /(1-a)}}{L-g\left(w_{r}\right)},
$$

where $L_{u}(b)$ is the labor demand function in the manufacturing sector and obtained through the first-order condition of the profit maximization problem. This model can be reduced to two simultaneous equations in the two unknowns $\lambda$ and $w_{r}$. We draw the equilibrium in Figure 1. The first equation, (15), is the linear function of $w_{r}$ and its function has a positive slope. If we define the rural wage rate, which satisfy $L-g\left(w_{r}\right)=0$, as $\hat{w}_{r}$, then $\lambda$ $\rightarrow \infty$ as $w_{r} \rightarrow \hat{w}_{r}$. Also as $w_{r} \rightarrow \infty, \lambda \rightarrow L_{u}(b) / L$ because $\lim _{w_{r} \rightarrow \infty} g\left(w_{r}\right)=0$. Thus the second equation, (16), is 


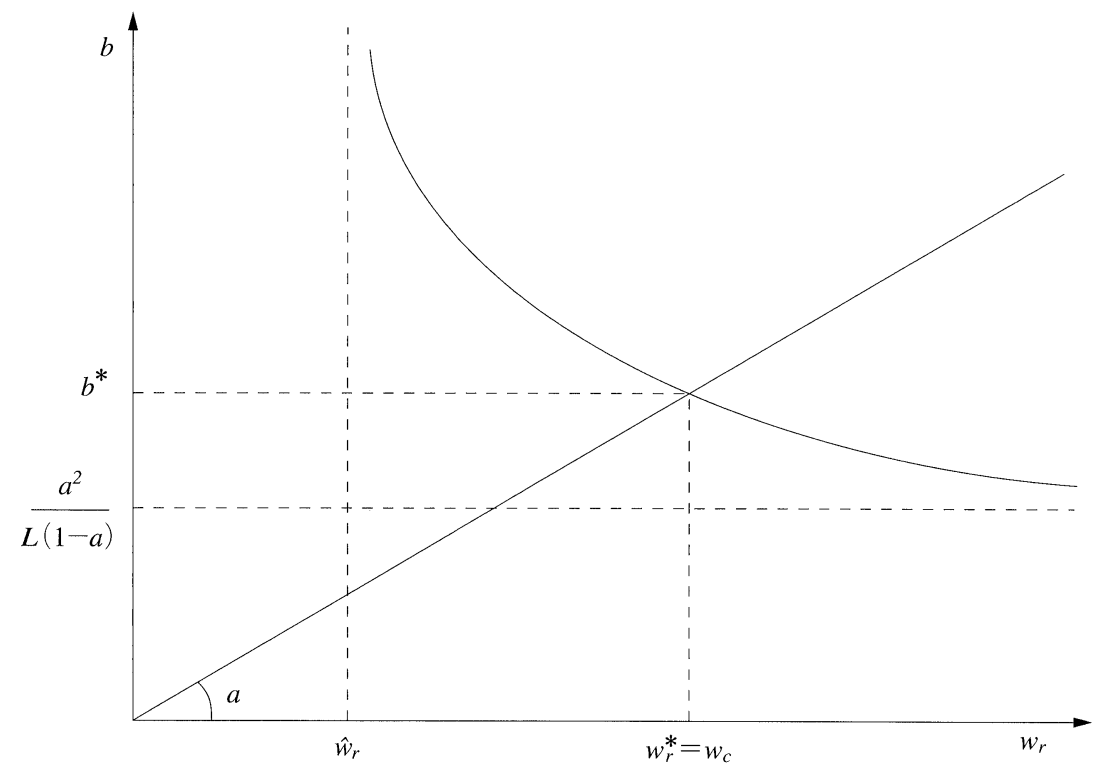

Figure 2 The existence of $b$ such as $\lambda=1$

drawn as the rectangular hyperbola of which the asymptotic lines are $w_{r}=\hat{w}_{r}$ and $\lambda=L_{u}(b) / L$. In Figure 1 , the urban employment rate and the rural wage rate in the equilibrium, respectively $\lambda^{*}$ and $w_{r}^{*}$, is expressed by a point that these two curves intersect.

Next, we show that an optimal unemployment allowance level exists at which there is no unemployment in the urban sector. In order to do so, we have to find the unique combination of $w_{r}$ and $b$, as $\lambda=1$ in (15) and (16) which means that the full employment is attained in this economy. Replacing (15) and (16) by $\lambda=1$, we obtain

$$
\begin{gathered}
b=a w_{r}, \\
b=\frac{a^{2}}{\left[L-g\left(w_{r}\right)\right]^{(1-a)}} .
\end{gathered}
$$

The function represented by (17) is linear in wr and has a positive slope. Moreover, the function in (18) is a rectangular hyperbola. That has the asymptotes of $b=a^{2} / L(1-a)$ and $w_{r}=\hat{w}_{r}$, because $b \rightarrow a^{2} / L(1-a)$ as $w_{r} \rightarrow \infty$ and $b \rightarrow \infty$ as $w_{r} \rightarrow \hat{w}_{r}$. These two curves are depicted as Figure 2. It is clear from Figure 2 that the intersection of the two curves designates the optimal unemployment allowance level, which leads to no unemployment.

\section{The case of an expected utility}

In considering the risk-averse individual, his utility function is assumed that $U=\ln w_{u}$, for simplicity. With this assumption, the utility function of trade union is reformulated to be $U^{T}=L_{u} \ln \left(\frac{w_{u}}{b}\right)$. Thus, substituting (3) for (12), we obtain 


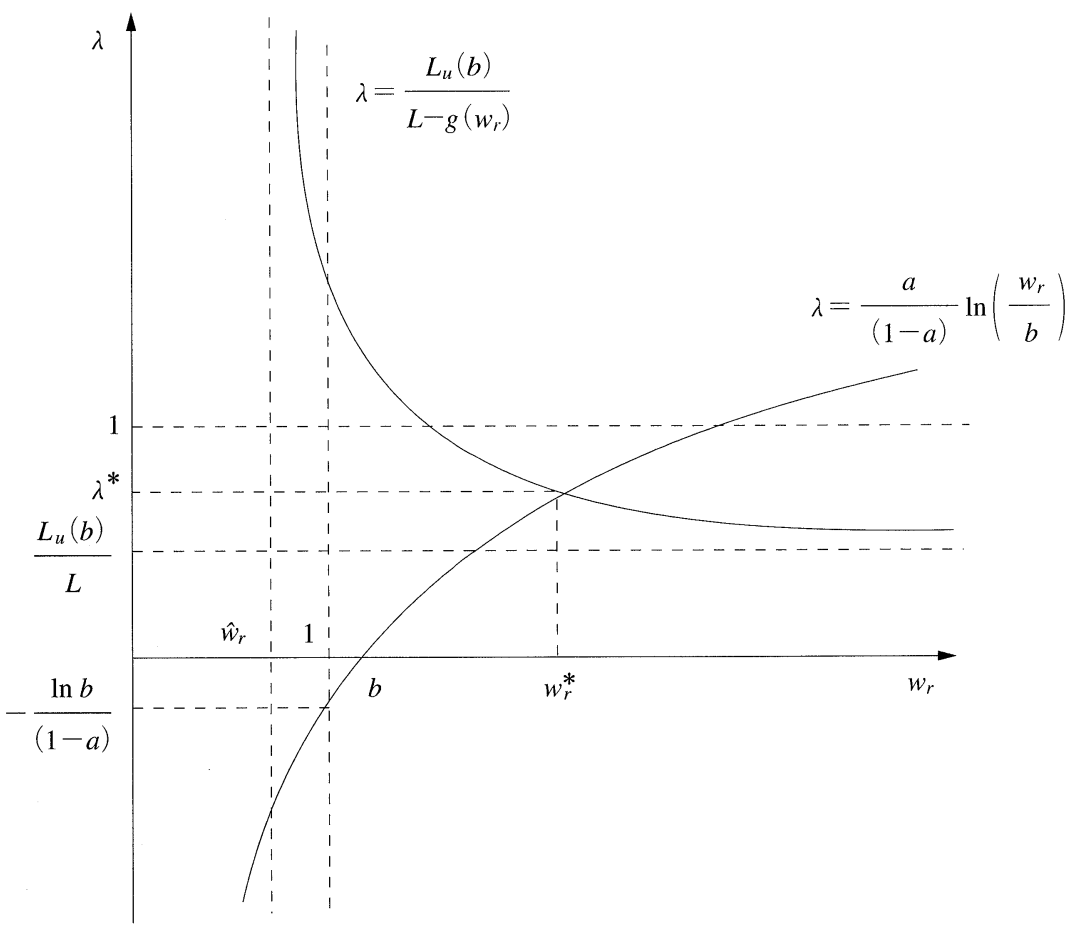

Figure 3 The determination of $\lambda$ and $w_{r}$

$$
\ln \frac{w_{u}}{b}=(1-a)
$$

The urban wage rate is expressed in a constant number that is multiplied by the level of an unemployment allowance. Now if we note that

$$
\begin{aligned}
& \lim _{b \rightarrow 0} w_{u}=0, \\
& \lim _{b \rightarrow \infty} w_{u}=\infty,
\end{aligned}
$$

there is an optimal level of the allowance, given that $w_{r}$ is $[0, \infty]$. The urban wage rate, $w_{u}$, maximizing the trade union utility also satisfies the feasibility condition, (4).

We determine the employment rate in the urban sector and the rural wage rate in the same way as the former section. At first, we consider the migration condition, (10). Note that $L_{u}>0$ implies $L_{u} / N_{u}>0$ if the condition of (5) holds. The migration condition is rewritten as follows.

$$
\ln \frac{w_{r}}{b}=\lambda(1-a) \text {. }
$$

Then, the equilibrium conditions are reduced to the following two equations:

$$
\lambda=\frac{1}{(1-a)} \ln \frac{w_{r}}{b},
$$




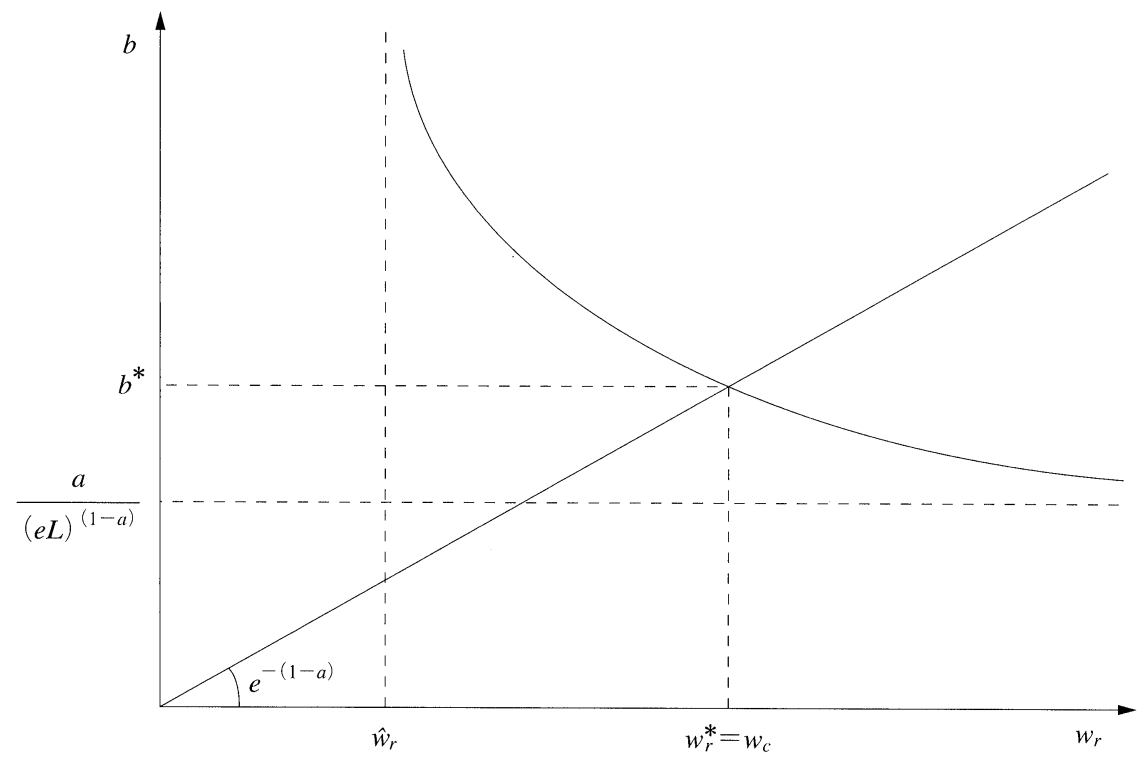

Figure 4 The existence of $b$ such as $\lambda=1$

$$
\lambda=\frac{\left(\frac{b e^{(1-a)}}{a}\right)^{-1 /(1-a)}}{L-g\left(w_{r}\right)} .
$$

These equations determine the two unknowns $\lambda$ and $w_{r}$. We can depict this determination as the figure 3 , in the case that $b>1$ and $\hat{w}_{r}<1$. If $0<b<1$, then $\lambda=-[\ln b /(1-a)]>0$ as $w_{r}=1$.

If we set $\lambda=1$, we obtain

$$
\begin{gathered}
b=\frac{a}{\left\{e\left[L-g\left(w_{r}\right)\right]\right\}^{(1-a)}}, \\
b=w_{r} e^{-(1-a)} .
\end{gathered}
$$

These relations are depicted like the figure 4 . We can express (25) as the linear function, as $e^{(1-a)}$ is constant. Now note that in (24) as $w_{r} \rightarrow \hat{w}_{r}, b \rightarrow \infty$ and as $w_{r} \rightarrow \infty, b \rightarrow a /(e L)^{(1-a)}$. The asymptotes of (24), therefore, are $w_{r}=\hat{w}_{r}$ and $b=a /(e L)^{(1-a)}$. This rectangular hyperbola and the linear function in (25) intersect at a unique $w_{r}^{*}$ between 0 and $\infty$, as displayed in the figure 4 .

It is, therefore, obvious that the unique optimal level of unemployment allowances exists, such as the urban employment rate is one, that is, the full employment is attained in this economy.

\section{Conclusion}

In this paper, we show that the unemployment allowance to urban worker can be the optimal policy. In Calvo (1978), the alternative wages in the objective function of the trade union is the rural wages and the migration is dependent on the expected income. They describes that the migration tax is the optimal policy in Calvo's mod- 
el. We introduce an unemployment allowance as the alternative wages and show that there is an optimum value of it even if the migration is dependent on the expected utilty. In Quibria's model, the two policies are needed to lead an economy to the first-best resource allocation, as formally shown in Chau and Khan (2001). In our model one policy is enough to achieve a first-best resource allocation differs from Quibria's model.

We assume that the government gives an unemployment allowance to the unemployed. In our model, the optimal unemployment allowance is positive. But the optimal unemployment allowance leads the economy to the first best resource allocation, where there is no unemployment. Therefore, the government doesn't have to pay the unemployment allowance.

We do not consider the informal sector in the urban area, while Quibria (1988) and Chau and Khan (2001) consider it in their model. They consider the case where unemployment is absorbed in the informal sector. In a future investigation, it would be worth incorporating unemployment in the urban area with the informal sector.

\section{References}

[ 1 ] Bhagwati, J.N. and T.N. Srinivasan (1974) “On Reanalysing the Harris-Todaro Model: Policy Rankings in the Case of Sector-Specific Sticky Wages”, American Economic Review, Vol.64, pp.502-508.

[ 2 ] Calvo, G.A. (1978) "Urban Unemployment and Wage Determination in LDC's: Trade Unions in the Harris-Todaro Model”, International Economic Review, Vol.19, pp.65-81.

[ 3 ] Chau, N.H. and M.A. Khan (2001) "Optimal Urban Employment policies: Notes on Calvo and Quibria”, International Economic Review, Vol.42, pp.557-568.

[ 4 ] Harris, J.R. and M.P. Todaro (1970) "Migration, Unemployment and Development: Two Sector Model", American Economic Review, Vol.60, pp.126-142.

[ 5 ] Oswald, A.J. (1985) "The Economic Theory of Trade Unions: An Introductory Survey", Scandinavian Journal of Economics, Vol.87, No.2, pp.160-193.

[6] Quibria, M.G. (1988) "Migration, Trade Unions and the Informal Sector: A Note on Calvo", International Economic Review, Vol.29, pp.557-563.

[ 7 ] Temple, J. R. W. (2005) "Growth and Wage Inequality in a Dual Economy", Bulletin of Economic Research, Vol.57, No.2, pp.145-169.

[ 8 ] Yabuuchi, S. (1996) "Urban Unemployment and Development Policy: The Introduction of an unemployment allowance", Economics and Politics, Vol.8, No.3, pp.241-249. 